\title{
Corrigendum / Erratum / Retraction
}

RETRACTION TO: Dhal, G.C., Dey, S., Prasad, R., Mohan, D. (2017). Simultaneous Elimination of Soot and NOX through Silver-Barium Based Catalytic Materials. Bulletin of Chemical Reaction Engineering \& Catalysis, 12 (1): 71-80 (doi:10.9767/bcrec.12.1.647.71-80)

\section{This article has been retracted by Publisher based on the following reason:}

Letter to Editor from Prof. James J. Spivey (Department of Chemical Engineering, Louisiana State University) who reported that a comparison of this paper with a previously paper published in Catalysis Today (258 (2015) 405-415, doi:10.1016/j.cattod.2015.02.024) shows significant duplication according to analysis by iThenticate shows $73 \%$ similarity, which is far more than acceptable. The authors have plagiarized part of the paper that had already published in [Catalysis Today (258 (2015) 405-415, doi:10.1016/j.cattod.2015.02.024)]. Based on clarification via email, Authors of the above paper have admitted their plagiarism to the previously published paper by Catalysis Today.

Editor of Bulletin of Chemical Reaction Engineering \& Catalysis acknowledged Prof. James J. Spivey due to the valuable Letter to Editor.

One of the conditions of submission of a paper for publication in this journal is that authors declare explicitly that their work is original and has not appeared in a publication elsewhere. Re-use of any data should be appropriately cited. As such this article represents a severe abuse of the scientific publishing system. The scientific community takes a very strong view on this matter and apologies are offered to readers of the journal that this was not detected during the submission process. 